\title{
The effectiveness of serum amyloid A for prediction of neonatal cholestasis associated with parenteral nutrition in premature infants
}

\author{
Hilal Özkan ${ }^{1}$, Nilgün Köksal ${ }^{1}$, Pelin Doğan ${ }^{1}$, İpek Güney-Varal ${ }^{1}$, Onur Bağc1 ${ }^{1}$, Taner Özgür ${ }^{2}$ \\ Departments of ${ }^{1}$ Neonatology and ${ }^{2}$ Pediatric Gastroenterology, Uludağ University Faculty of Medicine, Bursa, Turkey. \\ E-mail: hiozkan@hotmail.com \\ Received: 30th April 2018, Accepted: 3rd June 2018
}

SUMMARY: Özkan H, Köksal N, Doğan P, Güney-Varal İ, Bağcı O, Özgür T. The effectiveness of serum amyloid A for prediction of neonatal cholestasis associated with parenteral nutrition in premature infants. Turk J Pediatr 2019; 61: 26-33.

Parenteral nutrition (PN) has been widely used in premature infants untill enteral feeding can be tolerated. Cholestasis is an important complication of PN. The objective of this study was to evaluate the role of serial measurements of serum amyloid A (SAA) during PN and compare its' effectiveness with C-reactive protein (CRP) and procalcitonin (PCT). We also aimed to determine the risk factors for PN associated cholestasis (PNAC).

Premature infants ( $<34$ weeks' gestational age) who were started on PN during hospitalization were included in this prospective study. SAA, CRP and PCT levels were measured on days $0,3,7,14$, and 21 of PN in all infants. Infants who had PN for less than 2 weeks, who developed sepsis and/or necrotizing enterocolitis were excluded.

A total of 85 infants were included. The mean birth weight was $1226 \pm 329$ $\mathrm{g}$, and the mean gestational age was $29.4 \pm 1.8$ weeks. The birth weight of infants who developed cholestasis were significantly lower. Enteral nutrition was started significantly later in infants with cholestasis. CRP and PCT did not correlate with conjugated bilirubin levels at any time point. SAA levels on days 7 and 14 showed a significant correlation with conjugated bilirubin levels. SAA levels on day 7 was found to have the highest sensitivity for prediction of PNAC.

Low birth weight, late commencement of enteral feeding, and prolonged PN were the main risk factors for PNAC development. This is the first study that shows the predictive value of SAA for PNAC development. We suggest that SAA may be used as an accurate and useful biomarker for prediction of PNAC in high risk premature infants receiving PN.

Key words: parenteral nutrition associated cholestasis, serum amyloid-A, C-reactive protein, procalcitonin, premature infant.

Parenteral nutrition (PN) is a standard treatment used in the transition period to full enteral feeding in the first weeks of life in premature infants to achieve an inutero growth pattern. Although PN has several benefits in terms of growth and nutrition in premature infants, long-term use can cause various problems. Cholestasis is a frequent and serious complication related to $\mathrm{PN}$. It was reported to develop in $18 \%$ to $67 \%$ of infants with a history of 2-4 weeks of PN administration. ${ }^{1}$ In addition to the prolonged use of PN; prematurity, sepsis, delayed enteral nutrition, necrotizing enterocolitis (NEC) and surgical problems constitute the other risk factors for cholestasis in preterm infants. ${ }^{2-4}$

The mechanism of parenteral nutritionassociated cholestasis (PNAC) has not been fully understood. The proteins, lipids, and trace elements in PN solutions were suggested to 
induce an inflammatory cascade. ${ }^{5,6}$ Especially lipid solutions in PN may have an important role on the development of cholestasis. ${ }^{7,8}$ Various cytokines including tumour necrosis factor alpha (TNF- $\alpha$ ), interleukin (IL)-1 $\beta$, IL-6, IL-8, and acute phase reactants were reported to be increased as an inflammatory response. As a result of elevated cytokine concentrations, a decrease in bile flow was suggested to be associated with cholestasis development. ${ }^{9}$

As PNAC is an important cause of mortality and serious liver damage, early diagnosis and treatment is essential. Therefore, accurate biomarkers that can be used for early PNAC diagnosis are needed. Plasma cytokine and C-reactive protein (CRP) levels were reported to have predictive value for determination of PNAC in very low birth weight (VLBW) infants. ${ }^{10}$

Procalcitonin (PCT), the precursor protein of calcitonin, produced by monocytes and hepatocytes. It has been reported as a strong biomarker for infection and inflammation with higher sensitivity and specificity compared to CRP, especially for neonatal sepsis. ${ }^{11,12}$ PCT levels showed an increase in children with liver damage, especially in autoimmune diseases. ${ }^{13}$ However, no study investigated the role of PCT levels for prediction of PNAC in neonates.

Serum amyloid A (SAA), a member of the apolipoprotein family, mainly synthesized in the liver as a response to cytokine release by activated monocytes/macrophages after infection and tissue damage ${ }^{14}$. SAA was shown as an beneficial biomarker for the diagnosis and treatment of acute diseases (bacterial, viral, traumatic, rheumatic and ischemic heart) and neonatal sepsis ${ }^{12,15}$. Additionally, SAA was reported to be equal and/or superior to CRP in inflammatory abdominal pathologies such as pancreatitis in adults. ${ }^{16,17}$ We have shown SAA as an accurate biomarker for diagnosis and follow up of necrotizing enterocolitis (NEC). ${ }^{18}$ SAA was also determined to be as effective as CRP and PCT for NEC diagnosis. ${ }^{19}$

The best of our knowledge, there is no study that has evaluated the role of PCT and SAA for early diagnosis of PNAC in neonates. Therefore, the aim of this study was to investigate the role of SAA for diagnosis and follow up of PNAC in premature infants and compare its' effectiveness with CRP and PCT.

\section{Material and Methods}

Premature infants $(<34$ weeks' gestational age) who were who were admitted to the Neonatal Intensive Care Unit (NICU) of Uludag University, Faculty of Medicine between January 2013 and December 2016 were enrolled in this prospective observational study. The exclusion criteria were refusal of parental consent, major congenital malformation and chromosomal anomalies. The study protocol was approved by the local Ethics Committee (Date and report number: 2015-20/8). The study's financial source was Uludag University Scientific Research Project Unit. Informed parental consent was obtained for all infants. The demographic and clinical characteristics of the patients were all recorded.

On the first day of life, PN including $3 \mathrm{~g} /$ $\mathrm{kg} /$ day of $10 \%$ protein (Primene ${ }^{\circledR}$ ) and $1 \mathrm{~g} /$ $\mathrm{kg} /$ day of $\% 20$ olive oil-based lipid solution (Clinoleic $®)$ were started for all infants. Protein was increased to $4 \mathrm{gr} / \mathrm{kg} /$ day for infants with $2^{\text {nd }}$ day birth weight $<1000$ gr and $3.5 \mathrm{gr} / \mathrm{kg} /$ day for infants $<1500$ gr. The lipid was also gradually advanced daily to maximum $3 \mathrm{gr} /$ $\mathrm{kg} /$ day. In addition to routine hematological and biochemical tests; CRP, PCT, and SAA levels were measured on the $0^{\text {th }}, 3^{\text {rd }}, 7^{\text {th }}, 14$ th, and $21^{\text {st }}$ days of PN and continued weekly during PN administration in all infants. Infants who had PN for less than 2 weeks and who developed sepsis and NEC during this period were also excluded from the study. Figure 1 shows the flow diagram of the study.

Cholestasis was defined as a conjugated bilirubin concentration of $>1 \mathrm{mg} / \mathrm{dl}$ when total bilirubin

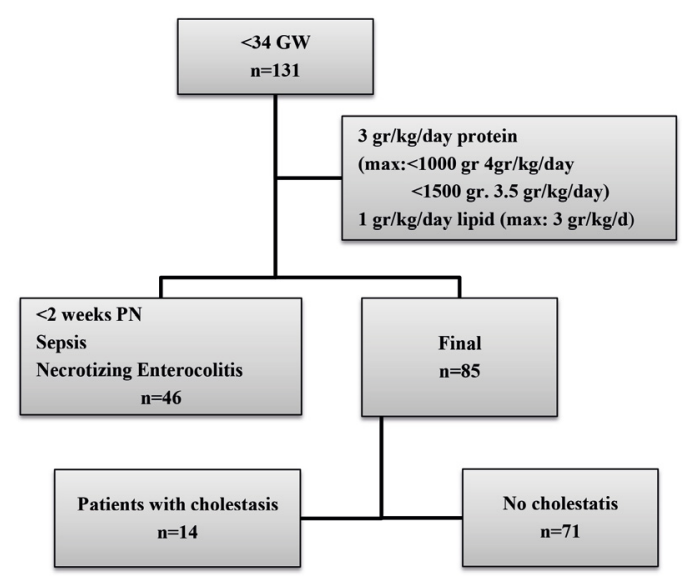

Fig. 1. Flow chart of study 
was $<5 \mathrm{mg} / \mathrm{dl}$ or a conjugated bilirubin concentration $>20 \%$ of total bilirubin when total bilirubin was $\geq 5 \mathrm{mg} / \mathrm{dl} .{ }^{20}$ Neonatal sepsis was diagnosed according to "International Sepsis Consensus" criteria. ${ }^{21}$ Necrotizing enterocolitis was diagnosed according to clinical and radiographic findings, and were classified according to modified Bell's criteria. ${ }^{22}$

Levels of CRP and SAA were determined by an immunonephelometric method using a BN II device (Dade Behring Marburg GMBH, Marburg, Germany). Total SAA was measured with a Siemens kit (Siemens, Deerfield, IL). PCT was measured by monoclonal immunoluminometric assay (Lumitest PCT; Brahm Diagnostica GMBH, Berlin, Germany), which is specific for the PCT molecule. In this assay, two different antibodies, one directed to calcitonin and another directed to katacalcin, were used. Levels of PCT $>0.5$ $\mathrm{ng} / \mathrm{mL}$ were accepted as pathological. Levels of SAA greater than $6.8 \mathrm{mg} / \mathrm{dL}$ were referred as positive, whereas levels of SAA below $6.8 \mathrm{mg} /$ $\mathrm{dL}$ were considered negative, according to the manufacturer instructions. Therefore, infants who had SAA levels greater than $6.8 \mathrm{mg} / \mathrm{dL}$ were considered to have abnormal SAA levels. Levels less than $0.5 \mathrm{ng} / \mathrm{mL}$ for PCT and CRP and $6.8 \mathrm{mg} / \mathrm{dL}$ for SAA were accepted as zero for statistical analysis.

Statistical Package for the Social Sciences (SPSS) for Windows 21.0 software (IBM Corporation, Armonk, NY) was used for evaluation of the relationship between the variables. Descriptive statistics were given as mean, standard deviation and percentage. The Shapiro-Wilk test was used to test the normal

Table I. Maternal and Neonatal Characteristics of Study Group.

\begin{tabular}{|c|c|c|c|}
\hline Characteristics & $\begin{array}{l}\text { Cholestasis group } \\
\qquad \mathrm{n}=14\end{array}$ & $\begin{array}{l}\text { No cholestasis } \\
\text { group } \\
\mathrm{n}=71\end{array}$ & $\mathrm{p}$ \\
\hline \multicolumn{4}{|l|}{ Maternal characteristics } \\
\hline Cesarean delivery, n(\%) & $12(85.7)$ & $57(80.3)$ & 0.6 \\
\hline Antenatal steroid, n(\%) & $6(42.9)$ & $33(46.5)$ & 0.48 \\
\hline Chorioamnionitis, n(\%) & $1(7.1)$ & $7(8.2)$ & 0.55 \\
\hline Premature rupture of membranes, $\mathrm{n}(\%)$ & $1(7.1)$ & $4(4.1)$ & 0.6 \\
\hline Preeclampsia, n(\%) & $5(35.7)$ & $26(36.6)$ & 0.5 \\
\hline \multicolumn{4}{|l|}{ Neonatal characteristics } \\
\hline Gestational age (week), mean \pm SD & $29.6 \pm 0.49$ & $29.0 \pm 0.21$ & 0.52 \\
\hline Birth weight (gram), mean \pm SD & $1044.6 \pm 73.4$ & $1262.4 \pm 39$ & 0.02 \\
\hline Males/females & $8 / 14$ & $30 / 41$ & 0.54 \\
\hline Apgar minute 1 & $5.6 \pm 2.5$ & $5.3 \pm 2.0$ & 0.4 \\
\hline Apgar minute 5 & $7.8 \pm 1.4$ & $7.5 \pm 1.6$ & 0.35 \\
\hline Small gestational age ( $<\% 10$ percentile), $\mathrm{n}(\%)$ & $5(35.7)$ & $18(25.4)$ & 0.4 \\
\hline Respiratuary distress syndrome, $\mathrm{n}(\%)$ & $11(78.5)$ & $61(85.9)$ & 0.05 \\
\hline Patent ductus arteriosus, $\mathrm{n}(\%)$ & $5(35.7)$ & $33(46.5)$ & 0.38 \\
\hline \multicolumn{4}{|l|}{ Feeding, $\mathrm{n}(\%)$} \\
\hline $\begin{array}{l}\text { Human milk } \\
\text { Preterm formula } \\
\text { Human milk+preterm formula }\end{array}$ & $\begin{array}{ll}5 & (35.7) \\
3 & (21.4) \\
6 & (42.9)\end{array}$ & $\begin{array}{ll}20 & (28.2) \\
18 & (25.4) \\
33 & (46.5)\end{array}$ & $>0.05$ \\
\hline Inititation of enteral feeding day, mean \pm SD & $6.5 \pm 1.1$ & $4.1 \pm 0.4$ & 0.04 \\
\hline Duration of parenteral nutrition, day, mean $\pm \mathrm{SD}$ & $40.9 \pm 6.7$ & $23.8 \pm 2.7$ & 0.04 \\
\hline
\end{tabular}


distribution of data. The categorical data were analyzed using a chi-square test. A MannWhitney test and a student's t test were used for comparisons between groups as appropriate. Logistic regression analysis was performed to determine the factors that independently could effect cholestasis development. Receiver operating characteristics (ROC) analysis was performed by MedCalc 16.8 statistical software. Values of $p<0.05$ were considered to be significant.

\section{Results}

A total of 85 premature infants were enrolled in the study. The mean birth weight was $1226 \pm 329 \mathrm{~g}$ and the mean gestational age was $29.4 \pm 1.8$ weeks. In this study, 14 infants (16.4\%) developed cholestasis. Although there was no significant difference in mean gestational age of cases with and without cholestasis, the birth weight of infants with cholestasis was significantly lower $(1044 \pm 73$ $\mathrm{g}$ vs $1262 \pm 39 \mathrm{~g})$. Enteral nutrition was started significantly later in infants with cholestasis $(6.5 \pm 1.1$ days) compared with no cholestasis group $(4.1 \pm 0.4$ days $)(p=0.04)$. The duration of PN was significantly longer in the cases with cholestasis (Table I).

Although the mean CRP levels measured at 3, 7,14 , and 21 were higher in the cases with cholestasis, this difference was not significant. Additionally there were no significant differences in infants with and without cholestasis in terms of PCT levels measured on days $0,3,7$ and

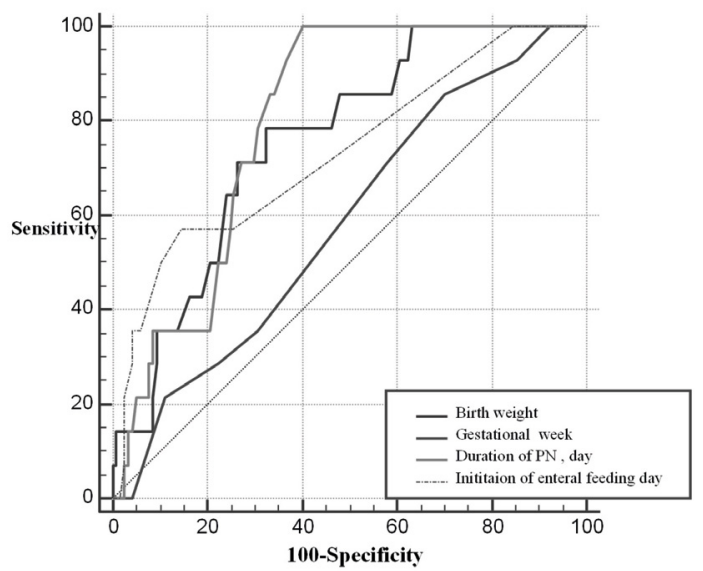

Fig. 2. ROC analysis for the prediction of parenteral nutrition-associated cholestasis
21; mean PCT levels measured on the $14^{\text {th }}$ day was significantly higher in infants with cholestasis $(5.5 \pm 3.2 \mathrm{ng} / \mathrm{ml})$ compared with the no cholestasis group $(1.1 \pm 0.4 \mathrm{ng} / \mathrm{ml})$ $(p=0.01)$. The mean SAA levels measured on the $7^{\text {th }}$ and $14^{\text {th }}$ days in infants with cholestasis were significantly higher. Although the mean SAA levels on the $21^{\text {st }}$ day were 2 -fold higher in the cases with cholestasis $(8.6 \pm 3.1 \mathrm{mg} / \mathrm{dl})$ compared to the cases without cholestasis $(4.1 \pm 1.2 \mathrm{mg} / \mathrm{dl})$, the difference was not significant. Table 2 shows the mean CRP, PCT and SAA levels obtained at different time points.

In the correlation analysis, although no significant relationship was determined between conjugated bilirubin and CRP and PCT levels on days $0,3,7,14,21$; significant correlations were determined between conjugated bilirubin levels and SAA levels on the $7^{\text {th }}$ and $14^{\text {th }}$ days. The mean conjugated bilirubin, alanine aminotransferase (ALT), aspartate aminotransferase (AST), and gamma glutamyl transferase (GGT) levels are shown in Table II.

As birth weight, PN period, commencement of enteral nutrition, $7^{\text {th }}$ and $14^{\text {th }}$ days SAA levels had a significant effect on PNAC development, cut off values and sensitivity and specificity for these parameters were determined by ROC and logistic regression analyses (Figs. 2, 3). A birth weight of $<1165 \mathrm{~g}$, starting enteral nutrition $>5$ days of life, and PN period $>18$

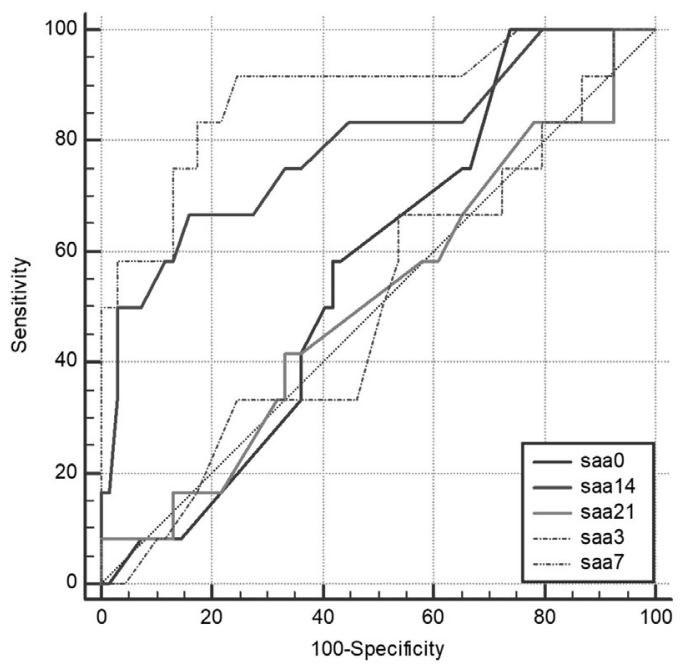

Fig. 3. SAA levels and ROC analysis for the prediction of parenteral nutrition-associated cholestasis 
Table II. Laboratory Tests in Study Groups.

\begin{tabular}{|c|c|c|c|}
\hline Laboratory Tests & $\begin{array}{l}\text { Cholestasis group } \\
\mathrm{n}=14\end{array}$ & $\begin{array}{l}\text { No cholestasis group } \\
n=71\end{array}$ & $\mathrm{p}$ \\
\hline $\begin{array}{l}\text { CRP mg/dl, mean } \pm \text { sd } \\
\text { 0.day } \\
\text { 3.day } \\
\text { 7.day } \\
\text { 14.day } \\
\text { 21.day }\end{array}$ & $\begin{array}{l}0.4 \pm 0.02 \\
1.7 \pm 0.58 \\
1.7 \pm 0.54 \\
1.6 \pm 0.62 \\
1.8 \pm 0.51\end{array}$ & $\begin{array}{l}0.6 \pm 0.11 \\
1.0 \pm 0.14 \\
1.4 \pm 0.32 \\
1.4 \pm 0.29 \\
1.2 \pm 0.24\end{array}$ & $>0.05$ \\
\hline $\begin{array}{l}\text { PCT } \mathrm{ng} / \mathrm{ml} \text {, mean } \pm \text { sd } \\
\text { 0.day } \\
\text { 3.day } \\
\text { 7.day } \\
\text { 14.day } \\
\text { 21.day }\end{array}$ & $\begin{array}{l}1.6 \pm 1.25 \\
6.2 \pm 2.5 \\
2.4 \pm 1.1 \\
5.5 \pm 3.2 \\
0.9 \pm 0.34\end{array}$ & $\begin{array}{l}8.3 \pm 2.6 \\
11.5 \pm 3.4 \\
6.0 \pm 3.0 \\
1.1 \pm 3.4 \\
0.6 \pm 0.15\end{array}$ & $\begin{array}{c}>0.05 \\
>0.05 \\
>0.05 \\
0.01 \\
>0.05\end{array}$ \\
\hline $\begin{array}{l}\text { SAA mg/dl, mean } \pm \text { sd } \\
\text { 0.day } \\
\text { 3.day } \\
\text { 7.day } \\
\text { 14.day } \\
\text { 21.day }\end{array}$ & $\begin{array}{l}3.9 \pm 0.27 \\
13.5 \pm 4.2 \\
20.3 \pm 3.8 \\
29.4 \pm 9.0 \\
8.6 \pm 3.1\end{array}$ & $\begin{array}{c}4.2 \pm 2.8 \\
11.9 \pm 2.7 \\
5.3 \pm 3.6 \\
5.6 \pm 4.2 \\
4.1 \pm 1.2\end{array}$ & $\begin{array}{r}>0.05 \\
>0.05 \\
0.0001 \\
0.0001 \\
>0.05\end{array}$ \\
\hline $\begin{array}{l}\text { Direct bilirubin, } \mathrm{mg} / \mathrm{dl} \text {, mean } \pm \text { sd } \\
\text { 0.day } \\
\text { 7.day } \\
\text { 14.day } \\
\text { 21.day }\end{array}$ & $\begin{array}{l}0.5 \pm 0.4 \\
2.5 \pm 1.7 \\
1.8 \pm 0.9 \\
1.7 \pm 0.6\end{array}$ & $\begin{array}{c}0.4 \pm 0.3 \\
0.46 \pm 0.1 \\
0.45 \pm 0.3 \\
0.4 \pm 0.3\end{array}$ & $\begin{array}{c}0.5 \\
0.0001 \\
0.0001 \\
0.0001\end{array}$ \\
\hline $\begin{array}{l}\text { ALT, U/L, mean } \pm \text { sd } \\
\text { 0.day } \\
\text { 7.day } \\
\text { 14.day } \\
\text { 21.day }\end{array}$ & $\begin{array}{l}11.4 \pm 8.9 \\
11.3 \pm 4.2 \\
19.2 \pm 15 \\
35.7 \pm 19\end{array}$ & $\begin{array}{l}10.2 \pm 9.1 \\
12.1 \pm 4.5 \\
10.5 \pm 6.4 \\
11.6 \pm 6.3\end{array}$ & $\begin{array}{c}0.4 \\
0.6 \\
0.003 \\
0.003\end{array}$ \\
\hline $\begin{array}{l}\text { AST, U/L, mean } \pm \text { sd } \\
\text { 0.day } \\
\text { 7.day } \\
\text { 14.day } \\
\text { 21.day }\end{array}$ & $\begin{array}{l}36.3 \pm 12 \\
31.8 \pm 10 \\
36.2 \pm 13 \\
67.1 \pm 17\end{array}$ & $\begin{array}{l}37.5 \pm 14 \\
33.8 \pm 23 \\
25.3 \pm 9.8 \\
27.9 \pm 16\end{array}$ & $\begin{array}{c}0.8 \\
0.7 \\
0.003 \\
0.001\end{array}$ \\
\hline $\begin{array}{l}\text { GGT, U/L, mean } \pm \text { sd } \\
\text { 7.day } \\
\text { 14.day } \\
\text { 21.day }\end{array}$ & $\begin{array}{l}216.7 \pm 98 \\
202.4 \pm 56 \\
223.5 \pm 54\end{array}$ & $\begin{array}{c}97.7 \pm 58 \\
104.3 \pm 14 \\
136.1 \pm 85\end{array}$ & $\begin{array}{c}0.001 \\
0.019 \\
0.04\end{array}$ \\
\hline
\end{tabular}

CRP: C-reaktive protein, PCT: procalcitonin, SAA: Serum amyloid-A

ALT: Alanine aminotranferase, AST: Aspartate aminotransferase, GGT: Gamma- glutamyl transferase

days were found to have significant predictive role for PNAC development. SAA levels $>6$ $\mathrm{mg} / \mathrm{dL}$ and $>11.7 \mathrm{mg} / \mathrm{dL}$ on days 7 and 14 day were also shown to be significantly related with PNAC development. Among all these contributing factors, SAA levels on $7^{\text {th }}$ day had the highest sensitivity for prediction of PNAC development (Table III).

\section{Discussion}

In this study; low birth weight, late commencement of enteral feeding, and prolonged PN were found as the main risk factors for PNAC development in premature infants. This study shows for the first time that SAA levels obtained at days 7 and 14 of PN were predictive of cholestasis.

PNAC is a common complication of $\mathrm{PN}$ in the NICU. It has been reported at varying rates of $7.4 \%$ to $84 \%$ in several studies 2,23 . The rate of PNAC was found to be $16.4 \%$ in our study, similar to the previous reports. Although the etiopathogenesis of PNAC is multifactorial, several risk factors including prematurity, low 
Table III. Cut-Off Points, Sensitivity, Specificity and Area Under The Curve For Risk Factors and Predictors for PNAC.

\begin{tabular}{lccccc}
\hline Variables, mean \pm sd & $\begin{array}{c}\text { Cut-off } \\
\text { point }\end{array}$ & Sensitivity & Specificity & AUC* & p \\
\hline Gestational age (week) & $<31$ & 85.71 & 29.91 & 0.58 & 0.26 \\
Birth weight (gr) & $<1165$ & 78.57 & 67.52 & 0.75 & $<0.0001$ \\
Inititation of enteral feeding day & $>5$ & 57.14 & 85.47 & 0.73 & 0.002 \\
Duration of PN, day & $>18$ & 100 & 59.83 & 0.79 & $<0.0001$ \\
SAA level, mg/l, 7.day & $>6$ & 92.86 & 76.15 & 0.89 & $<0.0001$ \\
SAA level, mg/l, 14.day & $>11.7$ & 71.43 & 87.10 & 0.83 & $<0.0001$ \\
\hline
\end{tabular}

${ }^{*}$ AUC $=0.5$ : prediction of cholestasis no better than chance; $A U C=1.0$ : perfect prediction; AUC $=$ area under the curve. PNAC: Parental nutrition associated cholestasis

birth weight, prolonged PN, sepsis, absence of enteral feeding, male gender, mineral trace and/ or plant phytosterol associated toxicity, type of protein and/or lipid formulations, n- 6 fatty acids were all suggested as the main risk factors for PNAC development in neonates. ${ }^{2,24,25}$ As PNAC $i$ associated with the immaturity of liver, it is more common and serious in infants with low birth weight and gestational age. ${ }^{2}$ Advances in minimal enteral nutrition and early feeding strategies in premature infants resulted with a decrease in both duration of PN and cholestasis development. ${ }^{26}$ Lack of early enteral nutrition was suggested to be associated with a decrease in secretion of gut hormones and growth factors that results with bile stasis. Bacterial overgrowth and endotoxins due to the intestinal stasis and decreased enterohepatic circulation were reported to lead to PNAC development. ${ }^{23}$ The contents of PN mixture were also suggested to be associated with PNAC development by causing toxicity, so duration of PN was reported as a risk factor. ${ }^{24}$ Similar to the literature, low birth weight, longer duration of $\mathrm{PN}$ and absence of early enteral feeding were found as the main risk factors for PNAC in our study. However, although clinical features may be used for prediction of PNAC development, these are not sufficient. Therefore, we need to identify biomarkers for early diagnosis and treatment of PNAC. Although several acute phase reactants including CRP, PCT and SAA have been widely used in the diagnosis and follow-up of neonatal sepsis, there is very limited data about the role of cytokine levels for prediction of PNAC in preterm infants.
Inflammation and infection was suggested to be associated with cholestasis development. The protein, lipid, and trace minerals in PN solutions have all been implicated in PNinduced inflammatory cascade. In the presence of inflammation, Kupffer cells produce proinflammatory cytokines including TNF- $\alpha$, IL- $1 \beta$, IL-8, and hepatocytes also produce cytokines and acute phase proteins in response to microbial products such as lipopolysaccharide (LPS) and endotoxins. These cytokines have been suggested to lead to cholestasis by downregulation of bile flow. ${ }^{10,27}$

DeMauro et al. ${ }^{10}$ investigated the role of CRP and some inflammatory cytokines for predicting PNAC in very low birth weight infants. The predictive value of these cytokines and CRP were evaluated at the $2^{\text {nd }}, 4^{\text {th }}$ and $6^{\text {th }}$ weeks of PN administration. CRP was found to be highly correlated with direct bilirubin levels and cholestasis. Median CRP concentrations showed an increase during the study period and they were significantly higher in the cholestasis group at the 2nd and 6th weeks of age. Median cytokine levels (IL-6, IL-8, IL-10 and IL-1 $\beta$ ) were also higher at all time points. The authors concluded that CRP was strongly associated with liver injury and might be used as a useful marker for the prediction of PNAC. ${ }^{10}$ In this present study, increased CRP levels were determined in infants with cholestasis, however it was not statistically significant. Therefore, our results were in accordance with the findings of DeMauro et al. ${ }^{10}$. Therefore, we suggest that increased CRP levels should alert physicians for development of PNAC in the absence of sepsis and/or NEC 
in preterm infants.

PCT was reported to have a very good diagnostic accuracy in neonatal sepsis 11, 28 . However, to our knowledge, no study had previously evaluated the role of PCT levels for the diagnosis of PNAC. We could not find a significant relationship between PCT levels and cholestasis in this study. Therefore, we suggest that PCT be used as an accurate biomarker for the prediction of PNAC. However, more studies are also required to confirm our data.

SAA is another acute phase protein that is mainly secreted by hepatocytes. SAA increases rapidly and significantly at the onset of inflammation and promptly returns to baseline levels with the resolution of the inflammation. SAA was established as an accurate and reliable marker for the diagnosis and follow up of neonatal sepsis and NEC. ${ }^{12,19}$ In addition, adult studies reported that the clinical value of SAA was equal or superior to CRP in inflammatory abdominal disorders such as acute pancreatitis 17,29. Hepatic SAA production by hepatocytes was determined to be stimulated by LPS and TNF- $\alpha$ in the presence of liver inflammation. SAA was shown to have a protective role during inflammation and stimulate several proinflammatory pathways. In a recent study, SAA was found to induce proliferation and inflammation in hepatic stellate cells ${ }^{30}$. Herein, SAA levels showed an increase from the $3^{\text {rd }}$ day of PN in the infants with cholestasis. The elevation in SAA concentrations were 4-5 fold higher in the cholestasis group and this increase was statistically significant on the $7^{\text {th }}$ and $14^{\text {th }}$ days of PN. A significant correlation was also detected between SAA and direct bilirubin levels on the $7^{\text {th }}$ and $14^{\text {th }}$ days of PN. SAA levels on these time points showed high sensitivity and specificity for prediction of PNAC development. As a result, we suggest for the first time that SAA may be a useful biomarker to predict PNAC in preterm infants under PN treatment. However, this finding must be confirmed with other clinical studies and more translational studies are required to elucidate the possible mechanisms of SAA increase in PNAC.

In conclusion; low birth weight, prolonged duration of PN and late commencement of enteral feeding were found as the main risk factors in PNAC. To our best of knowledge, this is the first study that showed a relationship between SAA levels and PNAC development. Therefore, we suggest that SAA may be used as an accurate and useful biomarker for prediction of PNAC in high risk premature infants receiving PN. However, larger studies are required to evaluate the relationship between SAA and PNAC-induced inflammation in neonates.

\section{REFERENCES}

1. Christensen RD, Henry E, Wiedmeier SE, Burnett J, Lambert DK. Identifying patients, on the first day of life, at high-risk of developing parenteral nutritionassociated liver disease. J Perinatol 2007; 27: 284-290.

2. Hsieh MH, Pai W, Tseng HI, Yang SN, Lu CC, Chen HL. Parenteral nutrition-associated cholestasis in prematüre babies: risk factors and predictors. Pediatr Neonatol 2009; 50: 202-207.

3. Klein CJ, Ravenis M, Kusenda C, Scavo L. Parenteral Nutrition-Associated Conjugated Hyperbilirubinemia in Hospitalized Infants. J Am Diet Assoc 2010; 110: 1684-1695.

4. Robinson DT, Ehrenkranz RA. Parenteral nutritionassociated cholestasis in small for gestational age infants. J Pediatr 2008; 152: 59-62.

5. Gura KM, Duggan CP, Collier SB, et al. Reversal of parenteral nutrition-associated liver disease in two infants with short bowel syndrome using parenteral fish oil: implications for future management. Pediatrics 2006; 118: 197-201.

6. Colomb V, Jobert-Giraud A, Lacaille F, Goulet O, Fournet JC, Ricour C. Role of lipid emulsion in cholestasis associated with long-term parenteral nutrition in children. J Parenter Enteral Nutr 2000; 24: 345-350.

7. Kurvinen A, Nissinen MJ, Andersson S, et al. Parenteral plant sterols and intestinal failure-associated liver disease in neonates. J Pediatr Gastroenterol Nutr 2012; 54: 803-811.

8. Cober MP, Teitelbaum DH. Prevention of parenteral nutrition-associated liver disease: lipid minimization. Curr Opin Organ Transplant 2010; 15: 330-333.

9. Kosters A, Karpen SJ. The role of inflammation in cholestasis: clinical and basic aspects. Semin Liver Dis 2010; 30: 186-194.

10. DeMauro SB, Kilpatrick LE, Gerdes JS, Abbasi S. Early inflammatory markers for prediction of cholestasis in very-low-birth-weight nfants. Neonatology 2012; 102: 229-234.

11. Koksal N, Harmancı R, Cetinkaya M, Hacımustafaoğlu $\mathrm{M}$. Role of procalcitonin and CRP in diagnosis and follow-up of neonatal sepsis. Turk J Pediatr 2007; 49: 21-29. 
12. Cetinkaya M, Ozkan H, Koksal N, Solmaz C, Hacımustafaoğlu M. Comparison of serum amyloid A concentrations with those of $\mathrm{C}$-reactive protein and procalcitonin in diagnosis and follow-up of neonatal sepsis in premature infants. J Perinatol 2009; 29: 225-231.

13. Korczowski B. Serum procalcitonin concentration in children with liver disease. Pediatr Infect Dis J 2006; 25: 268-269.

14. Malle E, Steinmetz A, Raynes JG. An acute phase protein and apolipoprotein. Atherosclerosis 1993; 102: $131-146$

15. Arnon S, Litmanovitz I, Regev RH, Bauer S, ShainkinKestenbaum R, Dolfin T. Serum amyloid A: an early and accurate marker of neonatal early-onset sepsis. J Perinatol 2007; 5: 297-302.

16. Rau B, Steinbach G, Baumgart K, Gansauge F, Gru“nert A, Beger HG. Serum amyloid A versus C-reactive protein in acute pancreatitis: clinical value of an alternative acute-phase reactant. Crit Care Med 2000; 28: $736-742$.

17. Mayer JM, Raraty M, Slavin J, et al. Serum amyloid A is a better early predictor of severity than C-reactive protein in acute pancreatitis. Br J Surg 2002; 89: 163-171.

18. Cetinkaya M, Ozkan H, Koksal N, Akacı O, Ozgur T. The efficacy of serial serum amyloid A measurements for diagnosis and follow-up of necrotizing enterocolitis in premature infants. Pediatr Surg Int 2010; 26: 835-841.

19. Cetinkaya M, Ozkan H, Koksal N, Akacı O, Ozgur T. Comparison of the efficacy of serial serum amyloid A, C-reactive protein and procalcitonin in the diagnosis and follow-up of necrotizing enterocolitis in premature infants. J Ped Surg 2011; 46: 1482-1489.

20. Feldman AG, Sokol RJ. Neonatal Cholestasis. Neoreviews 2013; 1: 14.
21. Goldstein B, Giroir B, Randolph A. International Consensus Conference on Pediatric Sepsis. International Pediatric Sepsis Consensus Conference: definitions for sepsis and organ dysfunction in pediatrics. Pediatr Crit Care Med 2005; 6: 2-8.

22. Walsh MC, Kliegman RM. Necrotizing enterocolitis: treatment based on staging criteria. Pediatr Clin North Am 1986; 33: 179-201.

23. Kelly DA. Liver complications of pediatric parentera nutrition: epidemiology. Nutrition 1998; 14: 153-157.

24. Jolin-Dahel K, Ferretti E, Montiyeros C, Grenon R, Barrowman N, Jimenaz-Rivera C. Parenteral nutritioninduced cholestasis in neonates: where does the problem lie? Gastroenterol Res Pract 2013; 2013: 163632.

25. Premkumar MH, Carter BA, Hawthrone KM, King $\mathrm{K}$, Abrams SA. Fish oil based lipid emulsions in the treatment of parenteral nutrition associated liver disease: an ongoing positive experience. Adv Nutr 2014; 5: 65-70.

26. Chaudhari S, Kadam S. Total parenteral nutrition in neonates. Indian Pediatr 2006; 43: 953-964

27. Kosters A, Karpen SJ. The role of inflammation in cholestasis- clinical and basic aspects. Semin Liver Dis 2010; 30: 186-194.

28. Vouloumanou EK, Plessa E, Karageorgopoulos DE, Mantadakis E, Falagas ME. Intensive Care Med 2011; 37: 747-762.

29. Rau B, Steinbach G, Baumgart K, Gansauge F, Grünert A, Beger HG. Serum amyloid A versus C-reactive protein in acute pancreatitis: clinical value of an alternative acute-phase reactant. Crit Care Med 2000; 28: 736-742.

30. Siegmund SV, Schlosser M, Schwabe RF, et al. Serum amyloid $\mathrm{A}$ induces inflammation, proliferation and cell death in activated hepatic stellate cells. PLOsOne 2016; 11: e0150893. 